\title{
Dramatic Deep and Durable Remission of Acute Fulminant Ulcerative Colitis Achieved with Cyclosporine in a Patient Who Failed the Induction Intravenous Phase of Cyclosporine
}

\author{
Alicia Philippou $^{a} \quad$ Anam Rizvi $^{\mathrm{a}} \quad$ Adam Steinlauf $^{\mathrm{b}}$ \\ a Department of Internal Medicine, Mount Sinai Hospital, New York, NY, USA; bDepartment \\ of Gastroenterology, Mount Sinai Hospital, New York, NY, USA
}

\section{Keywords}

Fulminant ulcerative colitis · Cyclosporine · Failed induction

\begin{abstract}
Medical rescue therapy for patients with severe steroid-refractory ulcerative colitis (UC) consists of intravenous (IV) cyclosporine or infliximab and remains limited. Cyclosporine is used by fewer medical facilities due to comfort and need for close drug level monitoring, despite evidence that it can have dramatic benefits. In many tertiary centers it is accepted that after 3-7 days of treatment with IV cyclosporine without response, a patient will not respond to the therapy, and other modalities, namely surgery, should be considered. We present the case of a 36-year-old man with acute severe UC refractory to steroids and multiple biologics, who "failed" IV cyclosporine for 2 weeks, much longer than the usually accepted induction phase, and achieved remission with continuation of oral cyclosporine. This case demonstrates the possibility that continued therapy with cyclosporine for a longer duration than the currently
\end{abstract}

\begin{tabular}{ll}
\hline & Alicia Philippou \\
Department of Internal Medicine \\
Mount Sinai Hospital \\
1468 Madison Avenue, New York, NY 10029 (USA) \\
Alicia.philippou@mountsinai.org
\end{tabular}




\section{Case Reports in Gastroenterology}

Case Rep Gastroenterol 2021;15:147-153

DOI: $10.1159 / 000512426$

(c) 2021 The Author(s). Published by S. Karger AG, Basel www.karger.com/crg

Philippou et al.: Dramatic Deep and Durable Remission of Acute Fulminant Ulcerative Colitis Achieved with Cyclosporine

accepted timeline can lead to remission and avoidance of colectomy in properly selected and monitored patients.

(c) 2021 The Author(s)

Published by S. Karger AG, Basel

\section{Introduction}

Intravenous cyclosporine (IV CSA) is established as effective salvage therapy for severe steroid-refractory ulcerative colitis (UC) [1], with no difference in efficacy when compared with infliximab (IFX) [2]. While improvement with IV CSA can be dramatic, it is generally used only in academic centers given its risks (nephrotoxicity, hypertension, neurotoxicity, metabolic derangements, and infection) and need for close monitoring [3, 4]. For medically refractory UC patients who fail primary salvage therapy, approximately $29 \%$ require colectomy [4], an intimidating prospect. It is a currently accepted teaching that after 3-7 days of no response to IV CSA, there will likely be no subsequent response to the medication at all $[5,6]$. We report the unique case of a medically refractory patient with severe UC who had inadequate response to a prolonged 2-week course of IV CSA despite adequate blood concentrations and refused colectomy but achieved a deep and durable remission after continued treatment with oral CSA.

\section{Case Report}

A 36-year-old man with pancolonic UC was admitted for acute severe ulcerative colitis (ASUC) following 2 weeks of increasing bloody diarrhea, nausea, vomiting, and weight loss after discontinuation of vedolizumab. Prior to hospitalization he had failed treatment with multiple biologics. He had poor response to IFX and originally responded well to vedolizumab but responded poorly upon reinstatement. He received oral steroids at baseline, but 1 month prior to presentation self-discontinued for intolerable weight gain and pedal edema. Oral steroids were restarted a week prior to presentation without improvement. On arrival, he was severely dehydrated and malnourished with inability to tolerate oral intake, so IV fluids, total parenteral nutrition, and rectal mesalamine were started. His labs of note on presentation are described in Table 1. Abdomen and pelvis computed tomography revealed pancolonic moderate bowel wall thickening and submucosal edema. Given his acuity, surgery was consulted and offered ileal pouch anal anastomosis or permanent stoma; however, he refused surgery. Flexible sigmoidoscopy showed diffuse moderate inflammation (Mayo 2) with severely active chronic colitis on biopsy (Fig. 1). Given prior biologic failure, a treatment plan was created to begin CSA with bridge to 6-mercaptopurine. On day 12 , he was initiated on continuous IV CSA $2 \mathrm{mg} / \mathrm{kg}$ (goal serum level: $200-400 \mathrm{ng} / \mathrm{mL}$ ) with standard trimethoprim/sulfamethoxazole prophylaxis for Pneumocystis. His hospital course was complicated by multiple superficial and deep vein thromboses (right basilic, left basilic, brachial plexus veins) despite initial treatment with rivaroxaban and switch to enoxaparin. During a 14-day course of IV CSA, he continued to have multiple bloody bowel movements, nausea, vomiting, fluctuating C-reactive protein levels (47.9-3.3 mg/L then to $71.8 \mathrm{mg} / \mathrm{L}$ by day 12 of CSA treatment), and CSA levels from 144.7 


\section{Case Reports in Gastroenterology}

\begin{tabular}{l|l}
\hline Case Rep Gastroenterol 2021;15:147-153 \\
\hline DOI: 10.1159/000512426 & $\begin{array}{l}\text { @ 2021 The Author(s). Published by S. Karger AG, Basel } \\
\text { www.karger.com/crg }\end{array}$ \\
\hline
\end{tabular}

Philippou et al.: Dramatic Deep and Durable Remission of Acute Fulminant Ulcerative Colitis Achieved with Cyclosporine

to $584.3 \mathrm{ng} / \mathrm{mL}$ (with only 4 values being lower than goal). Repeat flexible sigmoidoscopy 7 days after initiation of IV CSA revealed disease progression to Mayo 3 (Fig. 2). The patient continued to defer surgery despite extensive family discussions, preferring to be discharged on oral CSA with consideration for colectomy at a later date. He was switched to oral CSA (200 $\mathrm{mg}$ ) from IV on day 15 of CSA treatment. Two weeks after discharge, he had successfully initiated clinical remission with twice daily mostly well-formed, nonbloody stools, with stable weight and improved appetite. He was started on 6-mercaptopurine (50 mg) with continuation of CSA (level of $264.3 \mathrm{ng} / \mathrm{mL}$ ). Three months after discharge, a sigmoidoscopy indicated UC in complete remission (Mayo 0) with biopsies in the transverse, descending, and sigmoid colon revealing chronic inactive colitis (Fig. 3). He has since remained in clinical remission without need for surgery for over a year.

\section{Discussion}

Treatment for steroid-refractory UC failing primary medical therapies remains challenging as demonstrated in this case. The efficacy of CSA for treating severe refractory UC is not a new concept. Most practicing gastroenterologists are aware of its efficacy but fail to offer this treatment option due to their inexperience with the drug, fear of its potential complications, and the belief that at best, it offers only a bridge to surgery. Once initiated, treatment protocols at large tertiary care inflammatory bowel disease centers often recommend switching from IV to oral CSA only after successful clinical response [6] defined as response at 3-7 days of IV treatment, since failure to respond in this time interval indicates that this drug will likely be ineffective. Our patient, with ASUC with multiple complications, seemingly had no response to IV CSA by day 14 of treatment and would normally have undergone colectomy as definitive treatment. In shared decision-making with the patient after extensive counseling about the risks of continuing therapy without surgery, he continued to defer surgery and chose treatment with oral CSA. This patient's course is important to report, as it has the potential to change the way we view the application of CSA for the treatment of severe, medically refractory UC. Our patient's response occurred well after the recommended waiting period of 3-7 days of IV therapy (14 days) and only after 2 additional weeks of oral therapy. His response was robust (remission was achieved endoscopically and microscopically) and durable, as he continues to remain in remission over 12 months later.

CSA mediates UC by selectively inhibiting T-cell-mediated IL-2 production [7]. The use of CSA has similar outcomes to IFX, with $70-80 \%$ achieving remission in the short term and approximately $40 \%$ of patients avoiding colectomy after 2 years [8]. Despite this, fewer physicians feel comfortable with reaching for CSA in the acute setting [8]. An Australian study found that CSA was less readily available and less frequently used than IFX in out-of-hours settings [9].

Some important considerations should influence the choice of using CSA. Kornbluth [8] found that CSA may be better in hyperacute, severe UC cases as its therapeutic level can be achieved in $24 \mathrm{~h}$. Also, much of the discomfort with using CSA was related to concern over side effect profile: Van Assche et al. [10] showed that using a lower dose of CSA at $2 \mathrm{mg} / \mathrm{kg}$ was

\section{Karger'=}




\section{Case Reports in Gastroenterology}

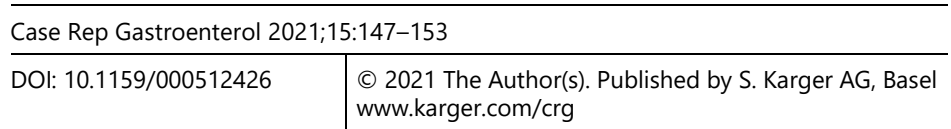

Philippou et al.: Dramatic Deep and Durable Remission of Acute Fulminant Ulcerative Colitis Achieved with Cyclosporine

effective for the medical treatment of severe UC and can provide an improved toxicity profile. When the NHS compared CSA and IFX treatment for severe UC, they found that CSA was significantly more cost-effective, while there were no differences in the clinical effectiveness, colectomy rates, incidence of side effects or mortality between the medications [11].

Severe steroid-refractory UC continues to be a threat to many patients and can be lifethreatening or lead to life-altering complications. Here, we highlighted a case in which continued treatment with CSA resulted in complete remission following inadequate response to a prolonged course of IV CSA. Thus, continuation of CSA further than the accepted 3-7 days of induction IV CSA despite inadequate response may be warranted and a potentially effective treatment of ASUC in carefully selected and continuously monitored patients who are refusing colectomy. Employing such a strategy in a patient as medically compromised as ours comes at an exceedingly large risk of sepsis and perforation and could only be advised under close supervision for similar patients who are refusing surgical intervention. However, the dramatic response achieved in our very ill patient after a "prolonged" course of therapy suggests that this approach may be a viable treatment option for those who are less acutely ill and are refractory to other conventional treatment options. Further studies are needed to evaluate the prevalence of this observation. Finally, this case highlights the utility of an older drug that is largely being forgotten or passed over with the advent of biologics and new small-molecule therapies.

\section{Statement of Ethics}

The subject has given their written informed consent to publish this case, including publication of images.

\section{Conflict of Interest Statement}

The authors have no conflicts of interest to declare.

\section{Funding Sources}

This case report has no funding sources.

\section{Author Contributions}

All authors contributed equally to this project including planning, writing, and editing of the manuscript. 


\section{Case Reports in Gastroenterology}

\section{References}

1 Lichtiger S, Present DH, Kornbluth A, Gelernt I, Bauer J, Galler G, et al. Cyclosporine in severe ulcerative colitis refractory to steroid therapy. N Engl J Med. 1994 Jun;330(26):1841-5.

2 Laharie D, Bourreille A, Branche J, Allez M, Bouhnik Y, Filippi J, et al.; Groupe d'Etudes Thérapeutiques des Affections Inflammatoires Digestives. Ciclosporin versus infliximab in patients with severe ulcerative colitis refractory to intravenous steroids: a parallel, open-label randomised controlled trial. Lancet. 2012 Dec;380(9857):1909-15.

3 Narula N, Marshall JK, Colombel JF, Leontiadis GI, Williams JG, Muqtadir Z, et al. Systematic Review and Meta-Analysis: Infliximab or Cyclosporine as Rescue Therapy in Patients With Severe Ulcerative Colitis Refractory to Steroids. Am J Gastroenterol. 2016 Apr;111(4):477-91.

4 Meier J, Sturm A. Current treatment of ulcerative colitis. World J Gastroenterol. 2011 Jul;17(27):3204-12.

5 Lichtiger S. The Role of Cyclosporine Therapy in Ulcerative Colitis Treatment. Gastroenterol Hepatol (N Y). 2006 Sep;2(9):624-6.

6 Higgins P, Waljee AK, Kinnucan J, Aldrich L, Del Valle J, Nostrant TT, et al. University of Michigan Severe Ulcerative Colitis Protocol. Version 2.9.3. University of Michigan; 2017 Oct 10.

7 Kountouras J, Zavos C, Chatzopoulos D. Immunomodulatory benefits of cyclosporine A in inflammatory bowel disease. J Cell Mol Med. 2004 Jul-Sep;8(3):317-28.

8 Kornbluth A. Cyclosporine versus infliximab for the treatment of severe ulcerative colitis. Gastroenterol Hepatol (N Y). 2011 Oct;7(10):677-9.

9 Laube R, Ali MS, Leong RW. Access to out-of-hours rescue therapy for acute severe ulcerative colitis in Australia. J Gastroenterol Hepatol. 2018 Sep;33(S2):98-9.

10 Van Assche G, D’Haens G, Noman M, Vermeire S, Hiele M, Asnong K, et al. Randomized, double-blind comparison of $4 \mathrm{mg} / \mathrm{kg}$ versus $2 \mathrm{mg} / \mathrm{kg}$ intravenous cyclosporine in severe ulcerative colitis. Gastroenterology. 2003 Oct;125(4):1025-31.

11 Williams JG, Alam MF, Alrubaiy L, Arnott I, Clement C, Cohen D, et al. Infliximab versus ciclosporin for steroid-resistant acute severe ulcerative colitis (CONSTRUCT): a mixed methods, open-label, pragmatic randomised trial. Lancet Gastroenterol Hepatol. 2016 Sep;1(1):15-24. 


\section{Case Reports in Gastroenterology}

Case Rep Gastroenterol 2021;15:147-153 (c) 2021 The Author(s). Published by S. Karger AG, Basel www.karger.com/crg

Philippou et al.: Dramatic Deep and Durable Remission of Acute Fulminant Ulcerative Colitis Achieved with Cyclosporine

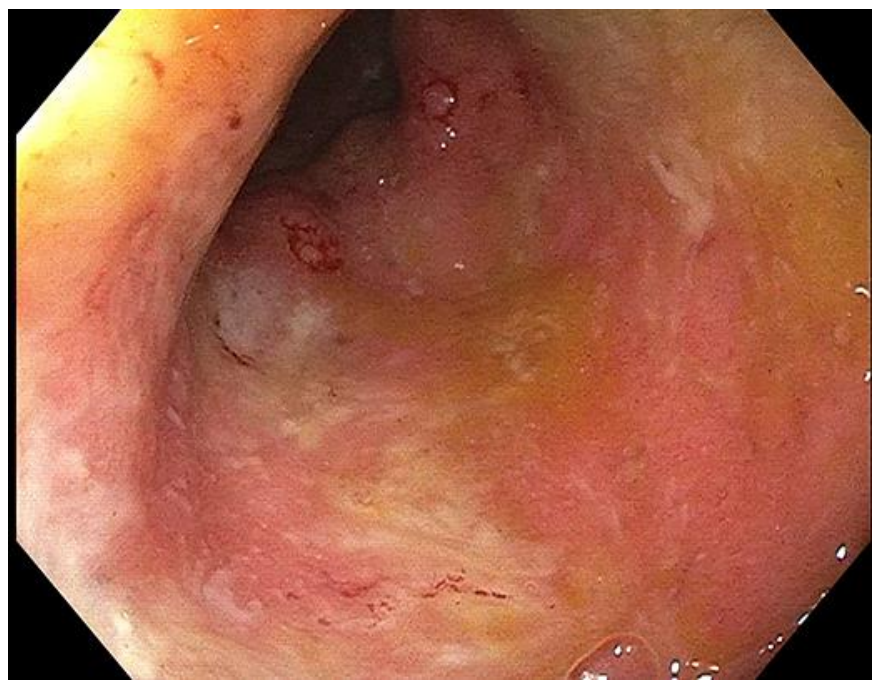

Fig. 1. Flexible sigmoidoscopy of the sigmoid colon with diffuse moderate inflammation with congestion, erosions, and friability, graded Mayo 2 (moderate, with marked erythema).

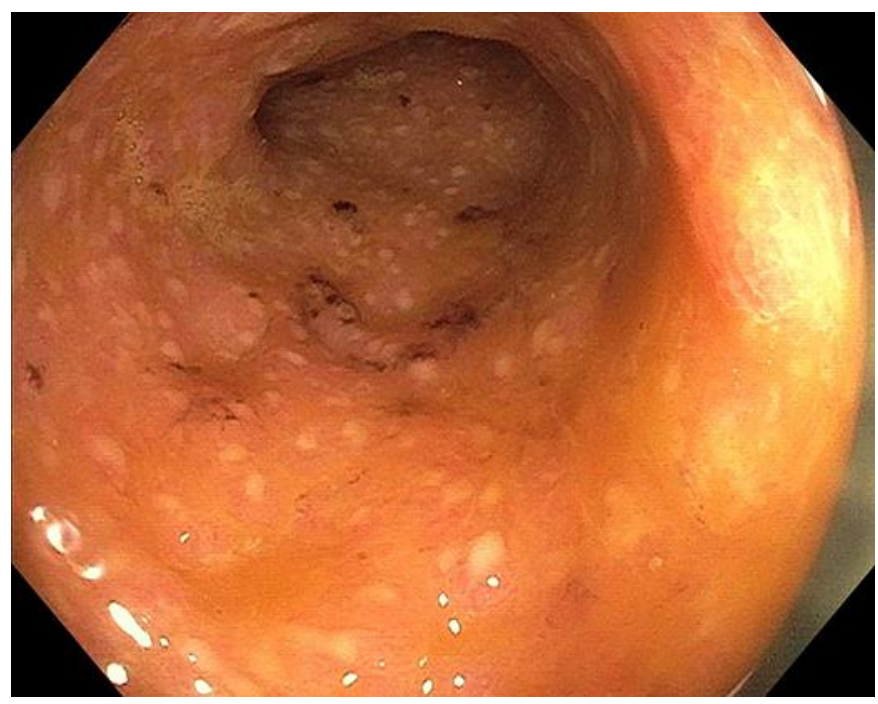

Fig. 2. Follow-up flexible sigmoidoscopy during hospitalization of the sigmoid colon with continuous areas of severely ulcerated mucosa, graded Mayo 3 (severe, with spontaneous bleeding, and ulcerations), indicative of worsening disease as compared to prior exam. 


\section{Case Reports in Gastroenterology}

Case Rep Gastroenterol 2021;15:147-153

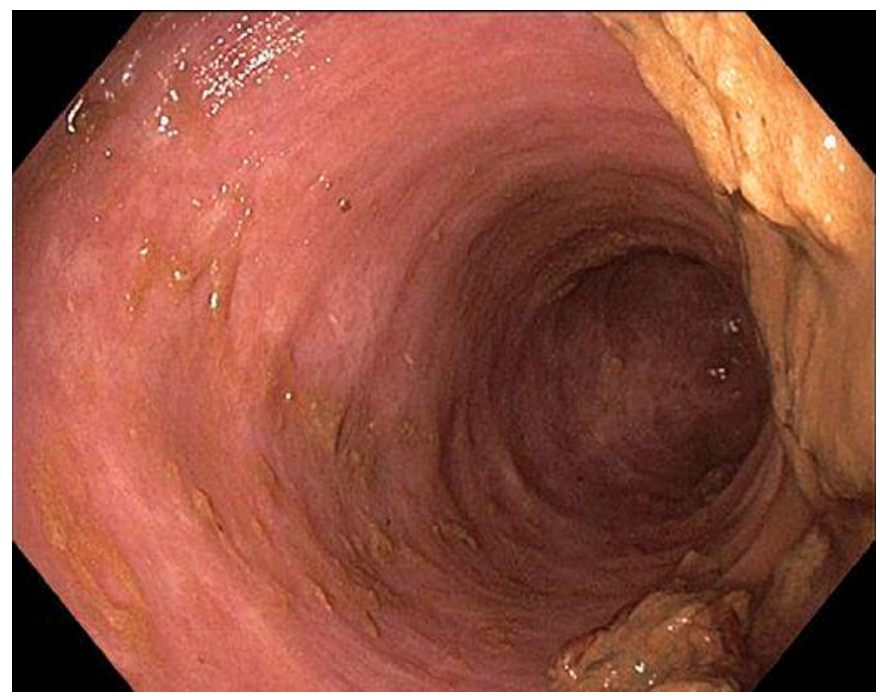

Fig. 3. Flexible sigmoidoscopy 3 months after discharge with inactive ulcerative colitis graded Mayo 0 . Disease was found to be in remission with mucosa that was normal in appearance without erosions, ulcers, friability, or bleeding.

Table 1. Presenting lab values

Erythrocyte sedimentation rate

C-reactive protein

Albumin

Hemoglobin

Platelets

Mean corpuscular volume

C. difficile antigen and toxin

Cholesterol

\author{
$62 \mathrm{~mm} / \mathrm{h}$ \\ $48.4 \mathrm{mg} / \mathrm{L}$ \\ $1.6 \mathrm{~g} / \mathrm{dL}$ \\ $9 \mathrm{~g} / \mathrm{dL}$ \\ $732 \times 10^{3} / \mu \mathrm{L}$ \\ $75.8 \mathrm{fL}$ \\ Negative \\ $157 \mathrm{mg} / \mathrm{dL}$
}

(c) 2021 The Author(s). Published by S. Karger AG, Basel www.karger.com/crg

Philippou et al.: Dramatic Deep and Durable Remission of Acute Fulminant Ulcerative Colitis Achieved with Cyclosporine 